\title{
Determination of Trichomonas vaginalis Positivity and Risk Factors in Patients with Urogenital Complaints
}

\author{
Nülüfer Erbil ${ }^{1}$, Ülkü Karaman ${ }^{2}$, Erdal Benli ${ }^{3}$, Deha Denizhan Keskin ${ }^{4}$, Abdullah Çırakoğlu ${ }^{3}$, \\ Pınar Naile Gürgörr ${ }^{5}$, Cemil Çolak ${ }^{6}$ \\ ${ }^{1}$ Ordu University, Faculty of Health Sciences, Department of Nursing, Ordu, Turkey \\ ${ }^{2}$ Ordu University, Faculty of Medicine, Department of Medical Parasitology, Ordu, Turkey \\ ${ }^{3}$ Ordu University, Faculty of Medicine, Department of Urology, Ordu, Turkey \\ ${ }^{4}$ Ordu University, Faculty of Medicine, Department of Obstetrics and Gynecology, Ordu, Turkey \\ ${ }^{5}$ Ordu University, Faculty of Medicine, Department of Histology and Embryology, Ordu, Turkey \\ ${ }^{6}$ İnönü University, Faculty of Medicine, Department of Biostatistics and Medical Informatics, Malatya, Turkey \\ Received: 23 December 2019, Accepted: 24 December 2019, Published online: 31 December 2019 \\ (C) Ordu University Institute of Health Sciences, Turkey, 2019
}

\begin{abstract}
Objective: In this study, the incidence and prevalence of Trichomonas vaginalis was aimed to help to overcome the difficulties in explaining the data for the regions and it was aimed to investigate its prevalence in different social groups in Ordu and its environs.

Methods Trichomonas Questionnaire Form and Personal Information Form of T. vaginalis were used in those who came to the urology and gynecology outpatient clinics from Ordu province and its environs. Urine sediment from the patients of urology outpatient clinic and vaginal smear specimen from the patients of gynecology outpatient clinic were collected and analyzed. All samples were examined by Direct Microscopic Investigation, culture, Giemsa and Papanikolau (PAPS) stain. Statistical analysis was performed with oneway and two-way chi-square test.

Results: In this study, 713 patients (202 males and 511 females) were examined. A total of 83 patients $(11.6 \%)$ were positive. There was a difference in the frequency distribution of the individuals with positive T. vaginalis with respect to age, gender, marital status, economic status, educational status, settlement, working status and home living status, knowledge status about infectious diseases, going to the bath, going to the pool, traveling, type of toilet, use of toilet paper, vaginal discharge, vaginal discharge status, drug usage, abortion, and knowledge status about sexually transmitted diseases and $T$. vaginalis $(\mathrm{p}<0.001$ ).

Conclusion: In this study, it was concluded that marital status, economic status, education level, settlement, working status and travel frequency may be effective in transmission of parasite. In this respect, it was inferred that the transmission of T. vaginalis can be reduced with in-service and public health trainings on the parasite transmission and the ways of prevention
\end{abstract}

Key words: Trichomonas vaginalis, urine, vaginal smear, urogenital,

Suggested Citation: Erbil N, Karaman U, Benli E, Keskin DD, C1rakoglu A, Gurgor PN, Colak C. Determination of Trichomonas vaginalis Positivity and Risk Factors in Patients with Urogenital Complaints. Middle Black Sea Journal of Health Science, 2019; 5(2):151-159

Address for correspondence/reprints:

Ülkü Karaman

E-mail: ulkukaraman44@ hotmail.com

Telephone number: +90 (553) 6185245

DOI: $10.19127 / \mathrm{mbsjohs.663599}$ 


\section{Introduction}

Trichomonas vaginalis is a flagellated protozoan that lives in the human urogenital system. There is only trophozoite form of it. The disease caused by it in the human urogenital system is called Trichomoniasis.

Trichomoniasis is a common infection all over the world. The rate of infection varies greatly from country to country, from community to community. The incidence is very high, especially in societies where women lack sexual hygiene precautions. According to the literature data, the incidence of Trichomoniasis in women varies between 10 and $90 \%$. Infection rate is reported as $9 \%$ in males (Unat et al; 1995). Due to the reasons like the use of different techniques and incomplete evaluation of known techniques, discrepancies between literature data are noteworthy in terms of the incidence of urogenital Trichomoniasis (Budak, 1987; Kuman, 1996; Cetinkaya et al, 2011). Although Trichomoniosis is a common infection, it has been reported that it is not possible to determine its incidence, and researchers have attributed the reason for the great variation in the rate of infection from country to country and from society to society to the fact that the methods used in diagnosis and the selected human populations are different (Toker, 1995; Daldal et al, 2002, Aral Akarasu, 2006). The direct transmission method of the parasite is the sexual route, but indirect transmission can also be observed (Karaman et al, 2006).

In the studies performed on the epidemiology of Trichomonas vaginalis in in Turkey, it is not possible to precisely state the incidence of this parasite due to the fact that it is locally limited (Kuman, 1996).

In this study, the incidence and prevalence of Trichomonas vaginalis in Turkey was aimed to help to overcome the difficulties in explaining the data for the regions and it was aimed to investigate its prevalence in different social groups in Ordu and its environs. In addition, it is aimed to gain the habit of confirming the diagnosis by using diagnostic methods, to increase the habit of using direct examination and culture methods, and to determine the prevalence of Trichomoniasis, to provide treatment and to define the risk factors of Trichomoniasis in patients with the complaint.

\section{Materials and Methods}

Material Collection and Performing
Questionnaire

Trichomonas Questionnaire Form which was developed in order to measure the prevalence of $T$. vaginalis with respect to various social conditions in the patients coming to the urology and gynecology outpatient clinics from Ordu province and its environs -the dependent variable of the study- and Personal Information Form again for the independent variables of the personal information in the study were used. The data of the study was collected by using face to face interview method between 10 June 2016-10 June 2017. Filling of data collection forms and obtaining samples took approximately 20-25 minutes. Male and female patients who agreed to participate in the study were asked to fill in the personal information form and trichomonas questionnaire form after signing the informed consent form. Illiterate individuals were asked to respond to forms after being read them. Literate participants answered the forms themselves. Samples were taken from the patients who participated in the study after the form was answered.

The social variables for Trichomoniosis examined in the study are limited to the characteristics measured by the Trichomonas questionnaire. It was assumed that women and men participating in the survey answered the questionnaire given to them sincerely and honestly and the questionnaire prepared was of sufficient validity and reliability.

The data collection process of the study was carried out in the urology and gynecology policlinics in Ministry of Health Ordu University Training and Research Hospital. The analysis process was realized in Parasitology Laboratory and Histology and Cytology Laboratory of Basic Sciences Department at Morphology Building of Faculty of Medicine, Ordu University.

\section{Methods Applied}

For parasite diagnosis, urine sediment from the patients administered to urology outpatient clinic and vaginal smear specimen from the patients administered to gynecology outpatient clinic were collected and analyzed. All samples were examined by Direct Microscopic Investigation, and Giemsa and Papanikolau (PAPS) stain. In addition, each sample was cultured on Cysteine-Peptone-LiverMaltose (CPLM) medium and evaluated after two days.

\section{Biostatistics Analysis}

Data was summarized in numbers and percentages. One-way and two-way chi-square test 
were used to statistical analysis of categorical variables. The statistical significance levels were set at $(\mathrm{p}<0.05)$. All statistical analyses were performed using IBM SPSS Statistics for Windows, version 26.0 (IBM, Armonk, NY, USA).

\section{Results}

In this study, 713 patients (202 males and 511 females) were examined. A total of 83 patients $(11.6 \%)$ were positive. 83 positive cases were detected by direct examination, staining method and culture method used in the diagnosis of $T$. vaginalis (Tablo 1). There were 79 positivity by direct microscopy, 81 positivity by staining method and 83 positivity by culture method.

The incidence of $T$. vaginalis was detected as $14.7 \%$ in women and $4 \%$ in men (Tablo 2).

The distribution and comparison of some characteristics of the study group according to $T$. vaginalis results were given in Table 3 .

When Table 3 was examined, it was found that there was a difference in the frequency distribution of age, gender, marital status, economic status, educational status, settlement, working status, home living status and knowledge status about infectious diseases groups in the individuals with positive $T$. vaginalis. In addition, the incidence of parasitic diseases increased as infectious diseases information status decreased ( $p<0.001)$. Again, the incidence of it in married was higher than single and widows $(\mathrm{p}<0.001)$. The presence of $T$. vaginalis showed significant changes with gender, working status and home living status ( $\mathrm{p}<0.05)$. In the study, higher positivity was observed in women compared to men. The analysis of the risk factors for $T$. vaginalis of the study group is given in Table $4 \mathrm{a}$ and $4 \mathrm{~b}$.

When Table $4 \mathrm{a}$ is analyzed, there was a significant difference in frequency distribution of $T$. vaginalis positive individuals with respect to going to hammam, going to pool, travel, type of toilet, toilet paper usage and discharge $(\mathrm{p}<0.001)$. The presence of $T$. vaginalis showed a significant change in terms of going to swimming pool, toilet type and the smell of discharge $(\mathrm{p}<0.05)$.

When Table $4 \mathrm{~b}$ is analyzed, there was a significant difference in frequency distribution of $T$. vaginalis positive individuals with respect to discharge status, drug usage, abortion, and knowledge level about sexually transmitted diseases and $T$. vaginalis $(\mathrm{p}<0.001)$. The presence of $T$. vaginalis showed a significant change in terms of having children and abortion status $(\mathrm{p}<0.05)$.

Table 1. T. vaginalis Distribution

\begin{tabular}{ccc}
\hline Presence status of T. vaginalis & $\mathrm{n}$ & $\%$ \\
\hline Negative & 630 & 88.4 \\
Positive & 83 & 11.6 \\
Total & 713 & 100 \\
\hline
\end{tabular}

Table 2. T. vaginalis Distribution with respect to Gender

\begin{tabular}{crrrrrr}
\hline \multirow{2}{*}{ Gender } & \multicolumn{2}{c}{ Presence status of T. vaginalis } & \multicolumn{2}{c}{ Total } \\
& Negative & Positive & & & \\
& $\mathrm{n}$ & $\%$ & $\mathrm{n}$ & $\%$ & $\mathrm{n}$ & $\%$ \\
\hline Woman & 436 & 85.3 & 75 & 14.7 & 511 & 71.7 \\
Man & 194 & 96.0 & 8 & 4.0 & 202 & 28.3 \\
\hline Total & 630 & 92.1 & 83 & 7.9 & 713 & 100 \\
\hline
\end{tabular}


Table 3. The distribution of $T$. vaginalis positivity of the study group according to demographic characteristics

\begin{tabular}{|c|c|c|c|c|c|c|c|}
\hline & \multicolumn{5}{|c|}{ Trichomonas vaginalis } & \multirow{3}{*}{$\mathrm{p}^{2}$} \\
\hline & & \multicolumn{2}{|c|}{ Positive } & \multirow{2}{*}{$\mathrm{p}^{1}$} & \multicolumn{2}{|c|}{ Negative } & \\
\hline & & $\mathbf{n}$ & $\%$ & & $\mathrm{n}$ & $\%$ & \\
\hline \multirow{4}{*}{ Age } & $0-19$ & 1 & 12.5 & \multirow{4}{*}{$<0.001$} & 7 & 87.5 & \multirow{4}{*}{0.529} \\
\hline & $20-34$ & 20 & 12.4 & & 141 & 87.6 & \\
\hline & $35-50$ & 36 & 13.4 & & 232 & 86.6 & \\
\hline & $>50$ & 26 & 9.5 & & 249 & 90.5 & \\
\hline \multirow{2}{*}{ Gender } & Woman & 75 & 14.7 & \multirow{2}{*}{$<0.001$} & 436 & 85.3 & \multirow{2}{*}{$<0.001$} \\
\hline & Man & 8 & 4.0 & & 194 & 96.0 & \\
\hline \multirow{3}{*}{ Marital Status } & Single & 3 & 6.5 & \multirow{3}{*}{$<0.001$} & 43 & 93.5 & \multirow{3}{*}{0.397} \\
\hline & Married & 76 & 12.3 & & 544 & 87.7 & \\
\hline & Widow & 4 & 8.5 & & 43 & 91.5 & \\
\hline \multirow{3}{*}{$\begin{array}{l}\text { Economic } \\
\text { Status }\end{array}$} & Good & 10 & 11.8 & \multirow{3}{*}{$<0.001$} & 75 & 88.2 & \multirow{3}{*}{0.116} \\
\hline & Medium & 69 & 12.7 & & 476 & 87.3 & \\
\hline & Low & 4 & 4.8 & & 79 & 95.2 & \\
\hline \multirow{4}{*}{$\begin{array}{l}\text { Educational } \\
\text { Status }\end{array}$} & Illiterate & 12 & 17.4 & \multirow{4}{*}{$<0.001$} & 57 & 82.6 & \multirow{4}{*}{0.085} \\
\hline & Primary education & 50 & 13.2 & & 329 & 86.8 & \\
\hline & High school & 15 & 8.2 & & 168 & 91.8 & \\
\hline & Higher education & 6 & 7.4 & & 75 & 92.6 & \\
\hline \multirow{5}{*}{$\begin{array}{l}\text { Education } \\
\text { Status of } \\
\text { Spouse }\end{array}$} & No spouse & 7 & 7.7 & \multirow{5}{*}{$<0.001$} & 84 & 92.3 & \multirow{5}{*}{0.268} \\
\hline & Illiterate & 2 & 4.8 & & 40 & 95.2 & \\
\hline & Primary education & 50 & 13.7 & & 314 & 86.3 & \\
\hline & High school & 18 & 11.8 & & 134 & 88.2 & \\
\hline & Higher education & 6 & 9.4 & & 58 & 90.6 & \\
\hline & Village & 19 & 13.1 & & 126 & 86.9 & \\
\hline Settlement & City & 20 & 9.8 & $0.001 * *$ & 185 & 90.2 & 0.580 \\
\hline & Province & 44 & 12.1 & & 319 & 87.9 & \\
\hline & Unemployed & 69 & 15.5 & & 376 & 84.5 & \\
\hline Working & Worker / officer / retired & 14 & 5.2 & & 254 & 94.8 & \\
\hline Condition & Officer & 0 & 0.0 & $<0.001$ & 0 & 0.0 & $<0.001$ \\
\hline & Retired & 0 & 0.0 & & 0 & 0.0 & \\
\hline Working & No spouse & 7 & 7.6 & & 85 & 92.4 & \\
\hline Condition of & Unemployed & 30 & 11.6 & $<0.001$ & 229 & 88.4 & 0.395 \\
\hline Spouse & Worker / officer / retired & 46 & 12.7 & & 316 & 87.3 & \\
\hline & Alone & 1 & 2.9 & & 34 & 97.1 & \\
\hline Home Living & Extended family & 5 & 4.6 & $<0.001$ & 103 & 95.4 & $0.008 * *$ \\
\hline & Nuclear family & 77 & 13.5 & & 493 & 86.5 & \\
\hline Another & Not extended family & 65 & 15.7 & & 348 & 84.3 & \\
\hline Woman if & Yes & 8 & 11.9 & $<0.001$ & 59 & 88.1 & $<0.001$ \\
\hline $\begin{array}{l}\text { Extended } \\
\text { Family }\end{array}$ & No & 10 & 4.3 & 0.001 & 223 & 95.7 & \\
\hline Information & Good & 11 & 8.0 & & 126 & 92.0 & \\
\hline Status about & Medium & 16 & 9.7 & & 149 & 90.3 & \\
\hline Infectious & Low & 21 & 17.1 & $0.001+\cdots$ & 102 & 82.9 & 0.114 \\
\hline Diseases & Absent & 35 & 12.2 & & 253 & 87.8 & \\
\hline
\end{tabular}

$\mathrm{p}^{1}$ :One-way chi-square test, $\mathrm{p}^{2}$ :two-way chi-square test

$* p<0.05$

$* * p<0.01$ 
Table 4a. The analysis of the risk factors of the study group with respect to $T$. vaginalis

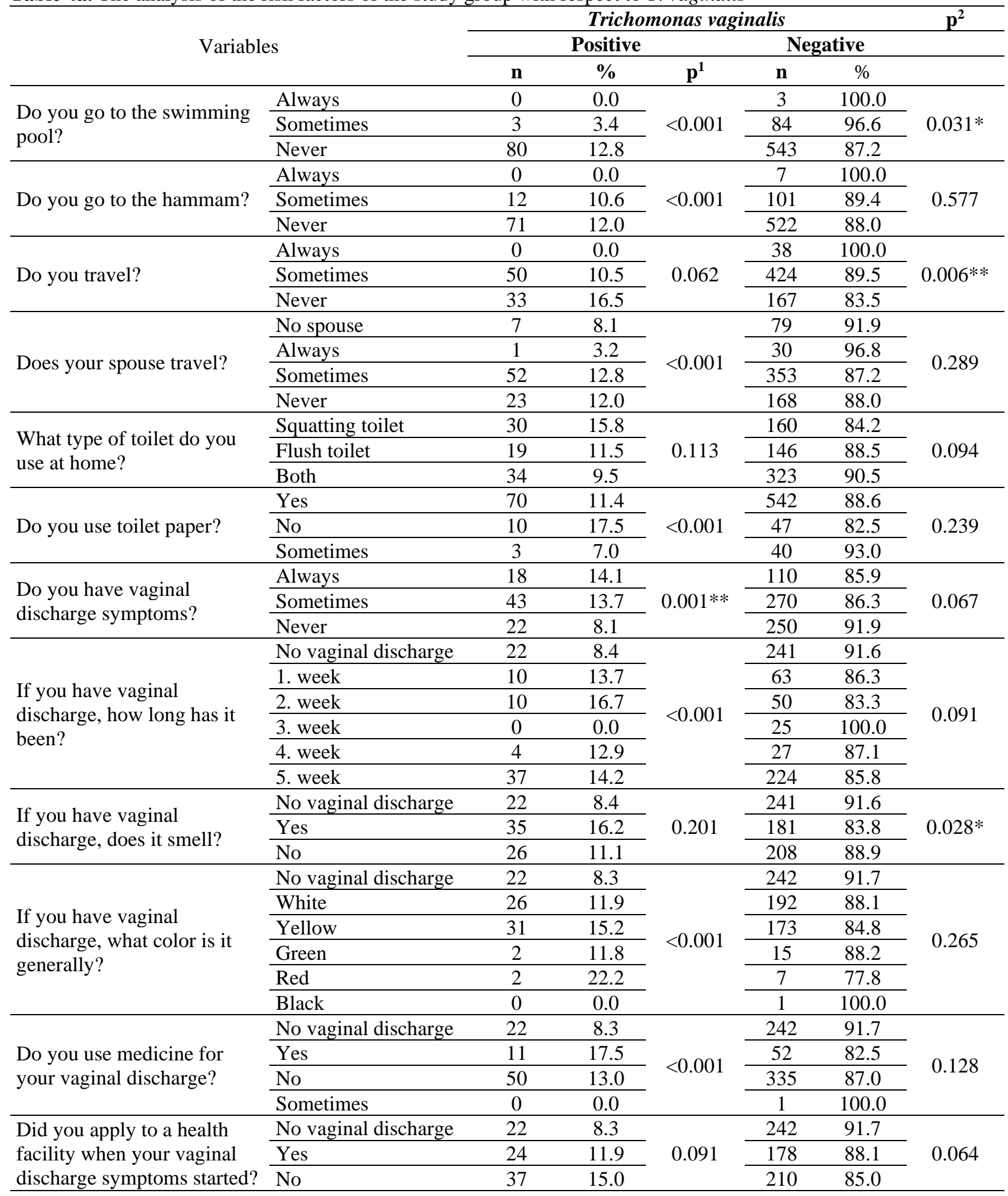


Table 4b. The distribution of Trichomonas vaginalis positivity according to study questions

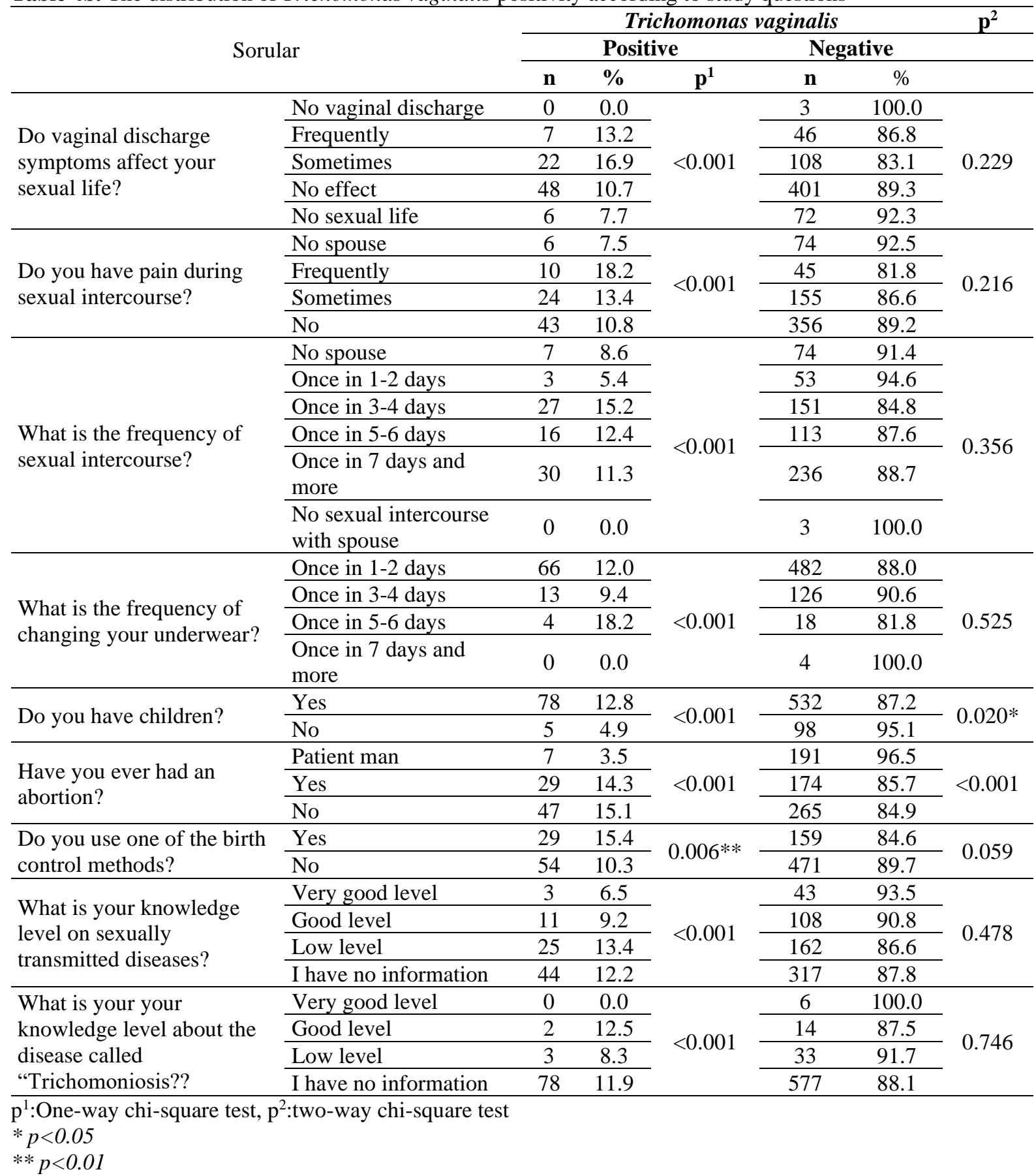

\section{Discussion}

T. vaginalis was found to be positive at different rates according to the study area, living conditions, and the population of the epidemiological study. According to the studies performed in different countries found in literature data, T. vaginalis was detected at rates of 9\% (Budak,1987) and 6\% (Daviez and Clay, 1992) in England, and \%3,2 in Sivas (Selvioglu et al, 2006), 6\% (Acholonu and Walker, 1998), 7\% (Madico et al.,1998) and 9\% (Paterson et al., 1998) in USA, 10\% (Vishwanath et al., 2000) and 7\% (Sharma et al.,1991) in India. In the studies conducted in different regions of Turkey, T. vaginalis has been reported at the rate of $7 \%$ (Budak, 1987) and 9\% (Sapmaz, 1985) in İzmir and its environs, 8\% (Kilimcioglu et al.,1998) in Manisa and its environs, 8\% (Ay and Yilmaz, 1994; Degerli at al., 1997) in Elazığ and its environs, 9\% (Sadr et al., 1992) in Adana, 9\% (Ay at al.,1996) Bursa, 7\% (Toker, 1995) in Ankara and its environs, 10\% (Turhanoglu et al, 1994) in Diyarbakır and 10\% (Dogan and Aygun, 1999) in Eskişehir. Again, Karaman et al. (2006) detected the parasite at a rate of $8.1 \%$ in a study performed upon women in 
Malatya. Similarly, Daldal et al. (2002), detected parasite in 14 of 33 bar girls working in the same region. In this study, 713 patients (202 males, 511 female) were examined. In total, parasites were detected in $83(11.6 \%)$ patients. In the present study, a significant association was observed between the percentage of parasite incidence and gender. When Table 2 is examined, it is observed that the incidence of parasites is higher in females than males. When the results of the study were evaluated, it was concluded that the incidence of $T$. vaginalis varies according to the social structure of the populations, the selected population and the time of study.

Staining and culture methods are preferred in the diagnosis of parasite (Ertabaklar et al., 2004; Culha et al., 2006; Field et al., 2016; Akyildiz et al., 2018). Değerli ve ark (2011) 1.9\% were positive with direct. In the present study, direct investigation, staining and culture methods were performed in parallel and similar results were obtained with each investigation.

The presence of $T$. vaginalis showed significant changes with gender, working status and home living status $(\mathrm{p}<0.05)$. In the study, higher positivity was observed in women compared to men. A significant increase was observed in the unemployed, according to both the presence or absence of parasites and the analysis among the positives. This situation can be explained that the epidemiology of the parasite may change with the socio-economic situation. Again, the percentage of incidence in the nuclear family was found to be higher. The aim of asking this question was thought that there may be indirect transmission since there may be more than one woman in the extended family. However, the rate of extended family found very low in the answers given to the questionnaire questions. This may be explained by the fact that the family status may be effective in the epidemiology of parasites.

It was found that there was a difference in the frequency distribution of age, gender, marital status, economic status, educational status, settlement, working status, home living status and knowledge status about infectious diseases groups in the individuals with positive $T$. vaginalis. In addition, the incidence of parasitic diseases increased as infectious diseases information status decreased.

The incidence of it in married women was higher than those of single and widows $(\mathrm{p}<0.001)$. This situation can be explained that active sexual life, economic status, education level, settlement and work status can be effective in parasite transmission.

When the responses to the questionnaire and the presence of the parasite were compared, there was no significant association with respect to frequency of going to hammam, renting or borrowing swimwear status, travel frequency of spouse, toilet paper usage status, bathing status, bathing style, the frequency of changing underwear, vaginal discharge complaint, color of the discharge, duration of vaginal discharge, disturbance status and pad usage status. However, a significant relationship was found in terms of the frequency of going to the swimming pool, the frequency of travel, the type of toilet in the workplace and the smell of the vaginal discharge. It has been reported that $T$. vaginalis can be transmitted via crowded pools and hammam (Unat et al, 1995; Sonmez Tamer, 2009). However, according to the questionnaire, the incidence of those who never went was high. In this respect, it has not been concluded whether going to the pool and hammam can be effective in the transmission or not. A significant relationship was found with respect to the type of toilet used, but it was not concluded whether the toilet type could be effective in the transmission or not since the incidence rate was high in unemployed ones. It has been reported that the parasite will be an odorous discharge (Cetinkaya et al., 2011) and the rate of being an odorous vaginal discharge in the presence of the parasite is high. This may be explained by the presence of odorous vaginal discharge, which may be suspected of the presence of the parasite. In the study, there was a significant relationship between the occurrence of the disease and the status of the out-of-drug treatment option $(\mathrm{p}=0.006)$. The percentage of $T$. vaginalis is higher in those who do not try drugs. This can be interpreted as the patients do not use any medication other than the doctor's control.

According to the answers given to the questionnaire in the study, there was a significant difference in frequency distributions of the groups of going to the swimming pool and hammam, renting or borrowing swimwear usage, travel frequency, type of workplace toilet, toilet paper usage, discharge complaints, frequency of discharge, color of discharge, pad usage, itching complaints, used drugs, bath status, status of child and abortion, knowledge status on sexually transmitted diseases and trichomoniasis in $T$. vaginalis positive individuals. In the study, the rate of parasite incidence was found to be higher in those using toilet paper, having occasional complaints of 
discharge, having vaginal discharge for 5 weeks or more and having white discharge. This can be explained by the fact that these factors may be effective in transmission of the parasite. It is reported in the literature data that the color of the discharge may be green (Cetinkaya et al., 2011), but in the present study, the percentage of parasite incidence was higher in those with white discharge. This may be due to the questionnaire questions and perceptions of the patients.

\section{Conclusion}

In this study, it was concluded that marital status, economic status, education level, settlement, working status and frequency of travel may be effective in transmission of parasite. Moreover, the fact that the incidence of parasites increases as the level of knowledge about sexually transmitted diseases and trichomoniosis decreases suggests that awareness studies should be performed. In this respect, it was concluded that the transmission of $T$. vaginalis can be reduced with in-service and public health trainings on the parasite transmission and the ways of prevention.

\section{Acknowledgments}

We would like to thank to the researchers admitting to participating in the study and Ordu University Scientific Research Projects Coordination Unit financially supporting this study (2016/A-1604). Also, we would like to thank to Asst. Prof. Dr. Yeliz Kaşko Arıcı helping on data analysis and Gamze Kaçmaz Yolalan, Büşra Kır and Şermin Top helping on data collection.

Ethics Committee Approval: Ethics committee approval was received for this study from Ordu Clinical Research Ethics Committee of Ordu University (Ethichs No: 2016/27).

Peer-review: Externally peer-reviewed.

Author Contributions: Concept - NE,ÜK Design NE,ÜK Supervision NE,ÜK, Materials NE,ÜK,EB,DDK,AÇ,PNG Data Collection and/or Processing - NE,ÜK, EB,DDK,AÇ,PNG Analysis and/or Interpretation - CÇ; Literature Review NE,ÜK, PNG Writing - NE,ÜK, EB,DDK,AÇ,PNG Critical Review - NE,ÜK, EB,DDK,AÇ,PNG

Conflict of Interest: No conflict of interest was declared by the authors.

Financial Disclosure: Ordu University Scientific Research Projects Coordination Unit financially supporting this study (2016/A-1604).

\section{References}

Acholonu A.D.W, Walker T, Trichomoniosis Surveillance in Mississippi. USA, 1996-1997, ICOPA IX 1998:713 -717

Akyildiz F, Ozcelik S, Ozpinar N, Karakus S. Comparison of three different culture methods in the diagnosis and investigation of frequency of Trichomonas vaginalis in women with the prediagnosis of vaginitis. Turkish Bulletin of Hygiene and Experimental Biology, 2018; 75(1): 43-52

Aral Akarsu G. Investigation of Trichomonas vaginalis in Patients with Nonspecific Vaginal Discharge. Türkiye Parazitol Derg 2006; 30: 1921

Ay S, Yilmaz M. Investigation of Trichomonas vaginalis in women with a vaginal discharge. Turkish Journal of Parasitology, 1994;18(2):101-103.

Ay YD, Oguz MC, Ozturk MO. Investigation of the prevalence of Trichomonas vaginalis and yeast cells in vaginal discharge. Turkish Journal of Parasitology, 1996;20(2):175-178.

Budak S. 1987. Epidemiology of Trichomoniasis. Trikomoniyaz, (Ed. Yasarol S) Turkey Parazitololoj Association of Broadcasting. No:7, s.19-20.

Cetinkaya U, Yazar S, Serin S, Hamamci B, Kuk S. Trichomonas vaginalis Positivity According to Type of Vaginal Discharge in Women. Turkiye Klinikleri J Med Sci. 2011;31(5):1094-9

Culha G, Hakverdi AU, Zeteroğlu Ş, Duran N. Investigation of the Prevalence of Trichomonas vaginalis in Women with Complaints of Vaginal Discharge and Itching. Turkish Journal of Parasitology, 2006; 30: 16-8.

Daldal N, Karaman U, Atambay M. The incidence of Trichomonas vaginalis among bar girls working in Malatya. Journal of Inonu University Medical Faculty, 2002;9:21-24.

Degerli S, Salk S, Malatyali E. Incidence in Sivas of Trichomonas vaginalis in Patients with Vaginitis. Turkish Journal of Parasitology, 2011;35(3):145-7

Degerli K, Lacin S, Ozbakkaloglu B, Sivrel A, Ozkutuk N, Ozbilgin A,. Investigation of the Prevalence of Trichomonas vaginalis and Candida spp. in Women with Complaints of Vaginal Discharge and Itching Turkish Journal of Parasitology, 1997;21(4):366-368.

Daviez AG, Clay JC. Prevalence of sexually transmitted disease infection in women allegingrape. Sex. Trans: Dis.19 (5) 1992 s:298300 
Dogan N, Akgun Y. 1999. The Relationship Between Trichomonas vaginalis and Presence of Yeast Cells II. National Parasitology Congress.6-10 Eylül 1999 Sivas Program and Abstracts, s.222.

Ertabaklar H, Ertug S, Kafkas S, Odabasi AR, Karatas E. Investigation of Trichomonas vaginalis in Women with a Vaginal Discharge. Turkish Journal of Parasitology, 2004;28 (4): 181-184.

Field N, Clifton S, Alexander S, Ison CA, Khanom $\mathrm{R}$, Sounders $\mathrm{P}$, et al. Trichomonas vaginalis infection is uncommon in the British general population: implications for clinical testing and public health screening. Sex Transm Infect, 2016;0:1-4.

Karaman U, Atambay M, Aycan OM, Daldal N. Survival of Trichomonas vaginalis in Various Environments and at Different Temperatures. Turkish Journal of Parasitology, 2004;28 (1): 1820.

Karaman U, Atambay M, Yazar S, Daldal N. Investigation of the Prevalence of Trichomonas vaginalis with Respect to Diverse Social Variables in Women (Malatya, Turkey). Turkish Journal of Parasitology, 2006;30(1):11-15.

Karaman U, Karadag N, Atambay M, Arserim Kaya NB, Daldal NUA. Comparison of cytological and parasitological methods in the diagnosis of Trichomonas vaginalis. Turkish Journal of Parasitology, 2008;32(4):309-312.

Kilimcioglu AA, Lacin S, Girginkardesler N, Degerli K, Ozbilgin A, Comparison of Diamond, Thioglycolate, TYM, CPLM Media, Direct Microscopy and Culture Methods for the Diagnosis of Trichomoniasis. Turkish Journal of Parasitology 1998;22(3): 239-242.

Kuman A, Altıntas N. Protozoon Diseases. Bornova-Izmir, 1996.

Madico GC, Quinn T, Rompalo A, Kelly T, Mckee JR, Charlotte A. Gaydos Diagnosis of Trichomonas vaginalis İnfection by PCR Using Vaginal Swab Samples. J. of Clin. Micro. 1998;36(11):3205-3210
Paterson BA, Tabrizi SN, Garland SM, Fairley CK, Bowden FJ. The tampon test for Trichomoniosis: A comparison between conventional methods and a polymerase chain reaction for Trichomonas vaginalis'in women. Sex. Trans:Inf. 1998 s:136-141

Sadr YE, Ozcan K, Arıdogan N, Koltas IS, Application of Rapid Latex Agglutination Method in the Diagnosis of Trichomonas vaginalis and Comparison of this Method with Microscopy, Culture and Staining Methods. Turkish Journal of Parasitology, 1992;16(3-4): 12-23.

Sapmaz G, 1985. Comparison of Trichomonas vaginalis (Donne, 1836) Obtained from Culture with Various Dye Methods. Master Thesis. Izmir.

Selvioglu A, Ozcelik S, Degerli S. The incidence of Trichomonas vaginalis in vaginal specimens from gynecologic patients. Turkish Journal of Parasitology, 2006;30(3): 177-175

Sharma P, Malla N, Gupta I, Ganguly NK, Mahajan RC. A comparison of wet mount, culture and enzyme linked immunosorbent assay for the diagnosis of Trichomoniosis in women Trop. Geogr Med. 1991;43(3):257-260.

Sonmez Tamer G, Keçeli Ozcan S, Yücesoy G, Gacar G. The Relation Between Trichomoniasis and Contraseptive Methods. Türkiye Parazitol Derg 2009; 33: 266-9.

Toker R. Evaluation of diagnostic methods in Trichomonas vaginalis and effects of parasite on social life. Ege Univ. Faculty of Medicine PhD Thesis Izmir, 1995

Turhanoğlu M, Turgut $\mathrm{H}$, Distribution of Microorganisms Isolated from Vaginal Swabs of Patients with Vaginitis. Turk Mikrobiyol. Cem. J, 1994;24(1-2): 59-61

Unat EK, Yucel A, Altas K, Samasti M. Medical parasitology of Unat. Cerrahpasa Med Fac. Found. Pub. :15 (5. edition) 1995

Vishwanath S, Talwar V, Prasad R, Coyaji K, et al. Syndromic management of vaginal discharge among women in a reproductive health clinic in. India. Sex. Trans: Infect. 2000;76 (4):303-307 